\title{
Theory, consequences and evidence of eroding population spatial structure in harvested marine fishes: a review
}

\author{
Lorenzo Ciannelli ${ }^{1, *}$, Jonathan A. D. Fisher ${ }^{2}$, Mette Skern-Mauritzen ${ }^{3}$, \\ Mary E. Hunsicker ${ }^{1}$, Manuel Hidalgo ${ }^{4}$, Kenneth T. Frank ${ }^{5}$, Kevin M. Bailey ${ }^{6}$ \\ ${ }^{1}$ College of Earth, Ocean and Atmospheric Sciences, Oregon State University, Corvallis, Oregon 97331, USA \\ ${ }^{2}$ Centre for Fisheries Ecosystems Research, Fisheries and Marine Institute of Memorial University of Newfoundland, \\ St. John's, Newfoundland and Labrador A1C 5R3, Canada \\ ${ }^{3}$ Marine Mammal Research Group, Institute of Marine Research, Bergen, Norway \\ ${ }^{4}$ Instituto Español de Oceanografía, Centre Ocenogràfic de les Balears, Moll de Ponent s/n, Palma 07015, Spain \\ ${ }^{5}$ Department of Fisheries and Oceans, Bedford Institute of Oceanography, Ocean Science Division, Dartmouth, \\ Nova Scotia B2Y 4A2, Canada \\ ${ }^{6}$ National Oceanic and Atmospheric Administration, Alaska Fisheries Science Center, Seattle, Washington 98115, USA
}

\begin{abstract}
In marine populations, spatial structure arises over a wide range of scales and forms hierarchical aggregations. Changing spatial structure can alter the demographic and life history trait variation within populations and subject individuals to both novel environmental conditions and interspecific interactions. Thus, changes in the spatial structure of marine populations can be a prelude to further changes in abundance and can affect the resilience and recovery potential of populations following anthropogenic and environmental perturbations. These observations underscore the importance of studying the spatial ecology of marine fish populations in order to (1) understand the underlying mechanisms that can lead to rapid alterations in population abundance and community interactions, (2) provide indicators of stock health, and (3) characterize the consequences of changing spatial patterns on population susceptibility to exploitation and environmental variability. Here, we synthesize the interacting factors that influence the formation, maintenance and erosion of spatial structure in marine fish populations and identify the further consequences of such erosion at the population and community levels. We emphasize human driven changes of population spatial structure for 3 levels of population genetic aggregation that are common in fisheries management scenarios, namely sympatric populations, metapopulations and panmictic populations. Case studies are presented for each level of aggregation. Throughout our review, we both summarize the factors that link spatial and temporal dynamics in marine populations and highlight the management and conservation implications of such linkages.
\end{abstract}

KEY WORDS: Spatial structure $\cdot$ Spatial ecology $\cdot$ Population dynamics $\cdot$ Fisheries Resale or republication not permitted without written consent of the publisher

\section{BACKGROUND AND OBJECTIVES}

All terrestrial and marine populations are, to varying degrees, spatially structured over a broad and hierarchical range of spatio-temporal scales (Goodwin \& Fahrig 1998) that span from small schools to demes in a metapopulation complex. Regardless of its scale, the spatial structure of a population is a key component of the population's ecology (Dunning et al. 1992). However, in fisheries science, rarely have results from spatial ecology been connected back to population abundance (Cadrin \& Secor 2009) nor 
have patterns of spatial variability been considered in revising boundaries of management units (Link et al. 2011). Yet there is increasing evidence that changes in marine fish species abundance over time are typically accompanied by equally dramatic and large-scale changes in spatial distribution patterns (Atkinson et al. 1997, Watanabe et al. 1997, McFarlane et al. 2002, Fisher \& Frank 2004, Bacheler et al. 2009), a characteristic that is similarly reflected in animal populations in general (Gaston et al. 2000). Moreover, changes in spatial patterns can subject individuals to a new set of environmental forcing and interspecies interactions and therefore can influence dynamics at the community level (Frank et al. 2007). These observations generate 2 simple but, as yet, unanswered questions. First, is a change of population spatial structure a mere manifestation of removing individuals, or is it also a prelude to further changes in population abundance? Addressing this question is a general ecology problem and involves an understanding of whether and how the spatial and temporal dynamics of populations are linked to each other. Second, if a change in population spatial structure precedes changes in population abundance, is the spatial structure of fish populations that are commercially harvested an attribute that is worth monitoring and preserving? The second question is an applied ecology problem, and it requires an understanding of whether indices of population spatial distribution can effectively supplement existing indices of population status.

In the present review article, we address both of these questions by examining the factors affecting the formation, maintenance and erosion of spatial structure in marine fish populations and the consequences of erosion at the population and community levels. Given the fundamental and applied nature of the topic, the paper is organized in 4 main sections: 'Theories', 'Consequences', 'Evidence' and 'Conservation'. In the 'Theories' section, we describe the processes thought to generate, maintain and disrupt population spatial structure across various levels of ecological and genetic aggregation. Because there is already a growing body of literature that deals with natural variations of spatial distribution of fish populations (see e.g. Ciannelli et al. 2008, Planque et al. 2011), in the present review, we streamline the description of natural variations to emphasize changes that are driven by exploitation. This is not to say that environmental changes do not matter; in fact, as we explain in our manuscript, these 2 sources of variability may interact. In the second section, 'Consequences', we review the potential impacts of changing spatial structure (human- or environmentally driven) on population and community dynamics. In the third section, 'Evidence', we present case studies from marine fishes that expand the main principles of the previous 2 sections. In the last section, 'Conservation', we link our findings with ongoing efforts to conserve harvested marine fish populations.

As a starting point, Berryman (2002) defined a population as a group of conspecific individuals inhabiting a region within which the dynamics are mostly controlled by birth and death processes. In our review, we expand on Berryman's (2002) definition to include 3 common and complex aggregation levels encountered in applied management situations: (1) sympatric discrete populations (e.g. Iles \& Sinclair 1982), (2) spatially complex populations, e.g. metapopulations (Smedbol et al. 2002) and source-sink populations (Pulliam 1988), and (3) panmictic populations (Table 1). In nature, these 3 levels of aggregations are present as a continuum rather than categorical groupings (Thomas \& Kunin 1999), and different

Table 1. Types of populations based on their genetic and demographic characteristics. B: per capita birth rate, D: per capita death rate, E: per capita emigration rate, I: per capita immigration rate. For each population type, we review a case study (see 'Evidence') listed in the last column

\begin{tabular}{|c|c|c|c|c|}
\hline Type & Definition & Demography & Genetic & Case study \\
\hline $\begin{array}{l}\text { Sympatric discrete } \\
\text { populations }\end{array}$ & $\begin{array}{l}\text { Reproductively and genetically } \\
\text { isolated populations, which may } \\
\text { occupy overlapping habitats, at least } \\
\text { during one phase of their life cycles }\end{array}$ & $\mathrm{B}+\mathrm{D} \gg \mathrm{E}+\mathrm{I}$ & Structured & $\begin{array}{l}\text { Alaska walleye pollock } \\
\text { Theragra chalcogramma }\end{array}$ \\
\hline $\begin{array}{l}\text { Spatially complex } \\
\text { populations } \\
\text { (metapopulation, } \\
\text { source-sink) }\end{array}$ & $\begin{array}{l}\text { Locally breeding subpopulations } \\
\text { (deme) which may be genetically } \\
\text { connected via dispersal }\end{array}$ & $\mathrm{B}+\mathrm{D} \geq \mathrm{E}+\mathrm{I}$ & $\begin{array}{l}\text { Homogenous and } \\
\text { weakly structured }\end{array}$ & $\begin{array}{l}\text { Eastern Scotian Shelf cod } \\
\text { Gadus morhua }\end{array}$ \\
\hline Panmictic population & $\begin{array}{l}\text { Interbreeding individuals that are } \\
\text { heterogeneously distributed over space }\end{array}$ & $\mathrm{B}+\mathrm{D} \ll \mathrm{E}+\mathrm{I}$ & Homogeneous & $\begin{array}{l}\text { Norwegian spring spawning } \\
\text { herring Clupea harengus }\end{array}$ \\
\hline
\end{tabular}


levels of aggregations can co-exist. For example, a panmictic or metapopulation complex can comprise components of a larger sympatric complex. However, it is important to realize that regardless of their level of aggregation, heterogeneous spatial distributions of populations occur because of the underlying spatial variability in the physical and biological environment (Brown et al. 1995), intra- and inter-specific interactions, and individual behavioral responses (Planque et al. 2011). The nonrandom spatial patterns of marine populations give rise to what we here define as the spatial structure. Another aspect of a population's spatial distribution that changes in relation to abundance is the habitat extent or occupancy (MacCall 1990). In the present review, we consider changes of both spatial structure and spatial occupancy because they are both influenced by exploitation. In doing so, we make 2 assumptions. First, the spatial structure of a population can be quantified by the deviation of the population spatial distribution from a fully random pattern, and its occupancy can be quantified by the spatial extent. Second, a population that has experienced erosion of spatial structure and occupancy has shrunk its geographical range and/or become more homogeneous over space.

\section{THEORIES}

\section{Mechanisms that generate and maintain population spatial structure}

The spatial structure of populations results from a tension between dispersal and isolation forces (e.g. Iles \& Sinclair 1982, Kokko \& Lopez-Sepulcre 2006) and from differences in demographic rates across the species' range (Dunning et al. 1992). However, the degree of spatial structuring in populations, the mechanisms that generate structure and the consequences of its erosion will vary among life history strategies and over scales (Goodwin \& Fahrig 1998). In marine environments, for example, we can expect that short-lived species inhabiting pelagic habitats exhibit more variability in spatial structure than longer-lived demersal or benthic species because of their short life cycle, earlier maturation, and association with more ephemeral environmental features. Likewise, we can expect that pelagic species may recover their spatial structure faster compared to long-lived demersal or benthic species, provided that the environmental conditions are favorable for such recovery.
With regard to scales, spatial structure gives rise to hierarchical levels of aggregation (Fauchald et al. 2000). In our review, we consider scales that separate ecological and genetic levels of population aggregation (Table 1). Sympatric but distinct populations are indicative of deep reproductive and genetic isolation among individuals belonging to different groups, which may take thousands of years to develop but which can be destroyed by minimal genetic exchange within just a few generations. Movement of reproductive individuals is therefore negligible between genetically distinguished populations and has minimal impact on the dynamics of each population, which are controlled mostly by internal birth and death processes. Such isolation is surprisingly common and increasingly revealed within marine species using molecular genetic techniques (Hauser \& Carvalho 2008). The lack of genetic separation does not necessarily preclude the existence of a sympatric complex. Many factors can blur the genetic signature of demographically isolated populations, such as markers used for examining the separation, population sizes, and the isolation time (Palumbi 2003, Hutchings et al. 2007, Knutsen et al. 2011). In contrast to this pattern of isolation, a metapopulation is defined by the presence of several locally breeding subpopulations linked to each other by individual dispersal and each having equal potential for independent extinction and re-colonization (Smedbol et al. 2002). In a metapopulation, the internal dynamics of each composing subunit (deme) are still dominant compared to the dynamics caused by individual dispersal, but the level of dispersal is such that the genetic signature among the composing demes is blurred (McQuinn 1997). Instances in which dispersal among the composing units of a spatially complex population have demographic consequences on other units are termed source-sink populations (Pulliam 1988). Finally, in panmictic spatially structured populations, movement of individuals prevents both local extinction and genetic structuring and therefore has a dominant impact on the local dynamics. It is important to note that spatial structure arises at any aggregation level but for different reasons. One could therefore consider spatial structure an aggregation-free property of populations.

There are 2 facets of spatial distributions that can be modified by human and environmental forcing, namely the population's occupancy and the level of spatial heterogeneity within that range. Landscape and hydrographic features that constrain individual dispersal and reproduction bound the geographic range of a population (Levin 1992). For example, the 
geographic range of sympatric populations or metapopulations is maintained by the mechanisms that generate reproductively or demographically isolated groups of individuals. These mechanisms include imprinting (Cury 1994), local retention of early life stages (Jones et al. 1999, Ciannelli et al. 2010), social interactions during migratory phases (Corten 2001), or habitat- and geographic-specific mating behavior (Rowe \& Hutchings 2003). Within the geographic range of a population, small-scale environmental forcing and individual behavior play dominant roles in determining the spatial structure. These variables may be considered as 'activating factors', promoting variability within the species' global or population's regional geographic range. For example, the spatial structure within a panmictic population is maintained by the underlying heterogeneity of the physical and biological environments (e.g. currents, patches of food or local prey depletion) and by behavioral interactions among the individuals of the same species (e.g. schooling and intra-specific competition) and other species (e.g. feeding aggregations and predation). Likewise, the spatial structure of a metapopulation or a sympatric complex of populations is maintained by the variation of demographic rates across the species range.

Factors affecting the spatial structure of marine populations can also be characterized based on whether they are density-independent or densitydependent. Generally, the response of individuals to density-dependent variables defines the population abundance-distribution relationship, while the effect of density-independent variables shapes the population's ecological niche (Brown et al. 1995). The Fretwell \& Lucas (1969) ideal free distribution (IFD) and the subsequent depiction of a basin model of marine fish distributions based on IFD (MacCall 1990) quantify the potential outcomes of these density-dependent spatial dynamics. Density-dependent spatial dynamics can promote expansion (or contraction) when the population reaches high (or low) levels of abundance, assuming that individuals settle on habitat patches in proportion to the local resources available, such that the habitat suitability or the individuals' fitness is equalized over the species spatial domain (Fretwell \& Lucas 1969). Within the area of distribution of a single panmictic population, spatial structure is also maintained through a preservation of the population age structure, as individuals of different ages/sizes and sexes are typically distributed differently over space due to stage-/age-specific requirements and size-related migration capabilities (e.g. Nøttestad et al. 1999, Holst et al. 2004, Fauchald et al. 2006). It follows that the spatial structure of a panmictic population can change in relation to cohort dominance; for instance, in pelagic fishes, where numerically dominant cohorts aggregate in certain areas, the sudden appearance of a large cohort can result in equally sudden changes of the population spatial structure (Huse et al. 2010).

Alternatively, or in addition to density-dependent dynamics, individuals are distributed over space following environmental preferences to optimize the use of spatially heterogeneous resources. Often, however, changes in population abundance, age structure, and occupancy also co-occur with largescale changes in environmental variables, such as water temperature (Swain 1999). In such circumstances, it becomes harder to disentangle the sources of variability in population distribution or the degree to which a change of environmental conditions facilitate or curtail a change of occupancy. Such a level of understanding is paramount for defining population management units (Link et al. 2011). As in other systems (Borregaard \& Rahbek 2010), identifying the cause-effect relationship between abundance and spatial distribution in exploited marine fishes remains a fundamental challenge (Shepherd \& Litvak 2004).

The concept of source-sink populations (Pulliam 1988) is also relevant in the context of understanding and preserving spatial structure because the presence of different demographic rates across space violates the assumptions of many fishery stock assessment models. This has led to calls for inclusion of spatially varying demographic rates (Cadrin \& Secor 2009). Furthermore, declining spatial structure of sourcesink populations may compromise the connectivity among demes, with implications for recovery dynamics (Lawton 1993). Spatial variation in demographic rates underlines the argument for the quantification and preservation of structure to maintain biocomplexity and insure against catastrophic losses at higher levels of ecological organization (Hilborn et al. 2003).

\section{Mechanisms that erode population spatial structures and occupancy}

Erosion or reduction of population spatial structure can arise due to human-induced and natural events or by a combination of both factors. Over short spatial and temporal scales, individuals respond to the natural variability of the forcing factors that affect their distribution. Individuals will react by moving to new habitats, feeding on different prey, and generally 
exploiting any available niche. This set of mechanisms acts parallel to those that are linked to exploitation, which causes local depletions (Bartolino et al. 2012), reduced spatial occupancy (Atkinson et al. 1997), and alteration of the population demographic and genetic structures (Brander et al. 2010). Both environmentally and human driven changes of population spatial structure and occupancy can be abrupt (e.g. regime shift and rapid transitions of population spatial distributions) and deleterious (e.g. invasive species, establishments of new trophic interactions, and age truncation). There are also synergies between the 2 drivers, e.g. a population that is heavily harvested is more likely to undergo further changes of its spatial structure in relation to environmental changes (Hsieh et al. 2010).

Depletion, induced by exploitation, can indeed contribute to the loss of spatial structure, especially when isolation forces historically prevailed over dispersal (Hauser \& Carvalho 2008). For example, exploitation that concentrates on spawning seasons and habitats has the potential to eliminate a single stock or a deme within a sympatric population system or a metapopulation complex, ultimately eroding the spatial structure. Similarly, localized depletion can dig a 'hole' within the geographic extent of a panmictic population, especially when migrants cannot refill that vacuum of space at the same rate at which individuals are being removed and/or when the habitat has been compromised (Bartolino et al. 2012). It is primarily the overharvesting of local populations/ aggregations (i.e. sub-units; often those closest to port suffer first) that erodes population structure. Harvest practices that are not concentrated in space and time (although they generally are; this property is what makes industrial fishing efficient) can also reduce population abundance, causing a spatial contraction. Spatial contractions are associated with fishery-induced stock declines (MacCall 1990, Atkinson et al. 1997, Walters \& Martell 2004). Similarly, if harvest is changing the demographic structure of a population, it can have consequences by changing spatial distributions and migration pathways and by causing a mismatch between early life stages and favorable environmental conditions. In general, multistock fishing is prone to declines of less productive stocks and those that are most vulnerable to sequential exploitation, i.e. the stocks in proximity to fishing ports are often overfished and then fishers move on to the next (Walters \& Martell 2004). The common outcome of these and other scenarios is the unintended overfishing of local populations and diminished spatial variability within marine populations.
Climate forcing can also contribute to the loss of population spatial structure. For example, climate change can alter dispersal pathways during early life stages (Bailey et al. 2008, Duffy-Anderson et al. 2012) and influence survival over different locations (Ciannelli et al. 2007a). Changing oceanographic conditions can inhibit population exchange and the survival of eggs and larvae by affecting their transport and retention in favorable areas (Bailey et al. 2008). Shifts in the distribution and phenology of fish and their prey can have a substantial effect on recruitment and production (Brander 2010). Also, populations or life stages that have specific habitat requirements may be severely affected by loss of favorable habitat due to changes in ocean conditions, including increasing temperatures, depleted oxygen and ocean acidification (Fabry et al. 2008, Voss et al. 2011). Such changes also reduce suitable spawning habitats and thus population reproductive success (Eby et al. 2005, Köster et al. 2005). As with the effects of fisheries, the causes of climate impacts may or may not be strictly related to space; if climatic variability results in large-scale changes in the abundance/ demographic structure, it will also cause changes in spatial distributions. There are many examples of changes in species spatial distributions that are attributed to large-scale changes in oceanographic conditions (Perry et al. 2005, Mueter \& Litzow 2008, Nye et al. 2009). These trajectories are likely to continue as climate change persists (Cheung et al. 2010).

\section{CONSEQUENCES}

The outcome of the processes that affect a population's spatial structure and its occupancy is based on traits that, to some extent, are adaptive and therefore increase the individual fitness (e.g. Fretwell \& Lucas 1969, MacCall 1990, Kokko \& Lopez-Sepulcre 2006). Eroding such structure interferes with how individuals interact with each other, with other species, and with the environment. This interference is likely to have consequences at the population and community levels and has in fact accompanied the collapse of many commercial stocks. Likewise, changes of trophic control in many marine ecosystems have been caused by changes of species abundance and distributions (e.g. Frank et al. 2007, Litzow \& Ciannelli 2007). In the following sections, for each of the 3 aggregations levels outlined in Table 1, we provide greater details on how erosion of spatial structure affects population and community interactions. 
Over larger spatial scales, the consequences of a loss in spatial structure can be particularly relevant for management and conservation purposes. Spatial structure is especially manifested during the spawning season, when reproductive individuals aggregate on spawning grounds. Iles \& Sinclair's (1982) seminal work using Atlantic herring populations indicated that populations exist as a combination of many substocks. The number of sub-stocks and abundance of each sub-stock is proportional to the number and size of geographic areas that allow retention during the early life stages. Thus, the variability of spatial abundance during spawning (or very early life stages) reflects the genetic structure of the population. Each subpopulation or deme can be adapted to the local environmental conditions, which may result in a heterogeneous spatial pattern in the life history traits (e.g. different somatic growth, maturing schedules, or reproduction phenology).

Since Iles \& Sinclair's (1982) work, numerous studies have revealed that genetic differentiation of many marine fishes is more complex and may occur at much smaller scales than once thought, raising concern about the mismatch between genetic population structure and current fisheries management units (Reiss et al. 2009). Fishing-induced depletion of subpopulations or demes will trigger a decrease in the genetic and phenotypic diversity, with consequences on the variety of ways in which populations can counteract environmental or human-induced variability. Evidence has been observed in different populations of anadromous fish, such as Alaskan salmon, in which the maintenance of life history diversity has been demonstrated to have clear implications for global dynamics and biomass trajectories (e.g. Schindler et al. 2010). Under conditions of locally adapted populations, abundance recovery after a local extinction may take a long time and probably a lot longer than the time estimated by models that do not take into account the spatial and genetic structure of the populations (Hutchings 2000, Heath et al. 2008, Murawski 2010). These consequences highlight the relevance of maintaining the 'biocomplexity' of exploited populations. That is, preserving different sub-populations or demes ensures high life history diversity and yields more temporal stability because of the independent but complementary dynamics (Hilborn et al. 2003, Olsen et al. 2008) (Fig. 1).

In the context of metapopulations, a consequence of loss of spatial structure is a reduction of the 'rescue effects', or reduced source-sink dynamics, due to the reduced dispersal of individuals from one deme to another (Gonzalez et al. 1998) (Fig. 1). Specifically, when local abundance is reduced, the ensuing migration of individuals will also be curtailed. This can have consequences for re-colonization, thus altering the metapopulation dynamics and making the metapopulation more likely to experience wide fluctuations and potential extinction. Thus, subunits within a metapopulation may feel the effect of depletion occurring elsewhere in the metapopulation complex. Habitat fragmentation also reduces the exchange of individuals among demes (Betts et al. 2006). This is particularly relevant for benthic or demersal species,

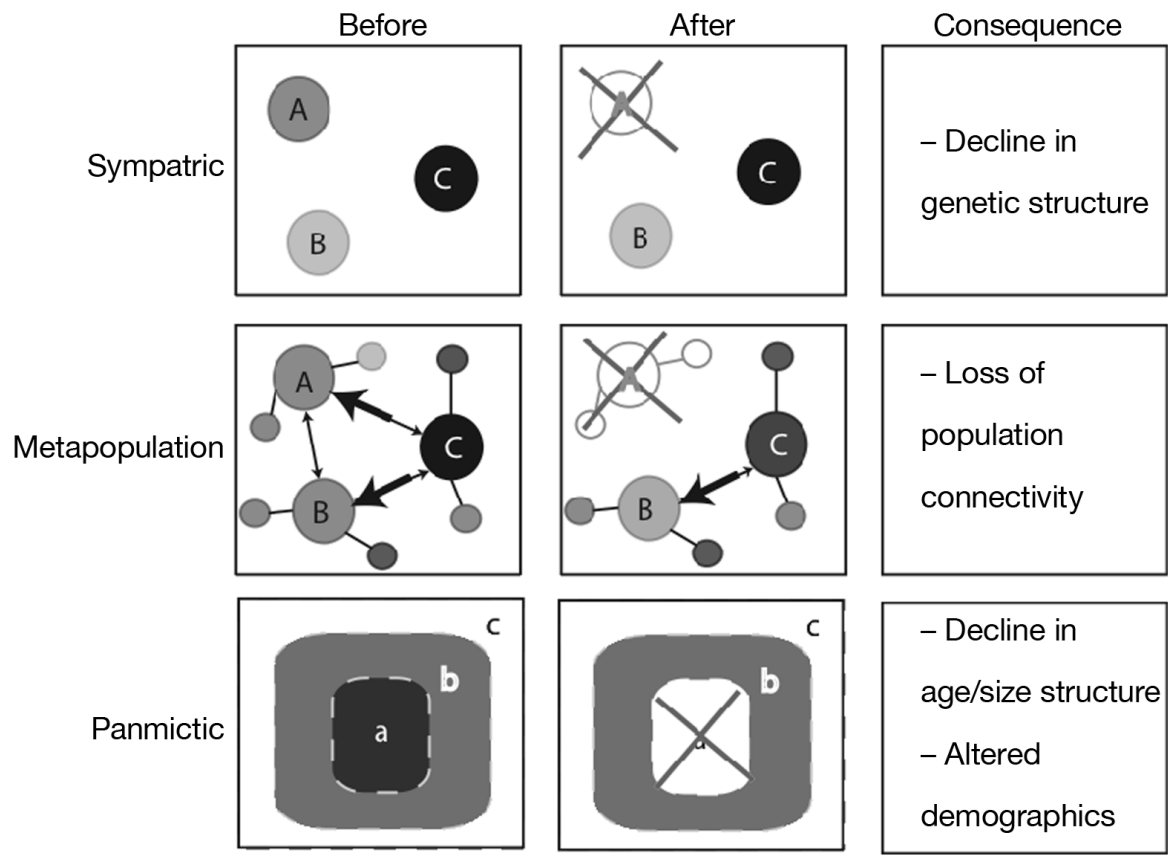

Fig. 1. Schematic representations of declines in 3 types of spatially structured populations and their consequences. A, B and C in the sympatric and metapopulation panels represent subpopulations and demes, respectively; $a, b$, and $c$ in the panmictic population represent areas of different local abundance. In each panel, shading represents relative abundance across space, and the weights of arrows among metapopulations indicates relative sub-population connectivity. Examples of these 3 types of population structural decline are described in 'Theories' 
which may move along corridors with specific characteristics (e.g. sediment size and infaunal assemblages). The process of colonization/recolonization may also depend on population thresholds being reached in a locale before the population expands outwards, perhaps being driven by density dependence, in search of new habitats (Ciannelli et al. 2012). This is similar to MacCall's (1990) geographic basin model, where a spillover occurs into initially less favorable habitats when the preferred habitat is occupied. There are several examples of such population behaviors, although abundance and geographic range may co-vary for a number of reasons (Shepherd \& Litvak 2004), and fishing on aggregations may erode the detection of preferred habitats (Shackell et al. 2005).

Another consequence reported for stocks which have experienced spatial erosion is a greater sensitivity to further spatial changes. For example, analyzing a long-term data set on larval distribution from the southern California region, Hsieh et al. (2008) showed that stocks that were more sensitive to environmentally driven changes in spatial distribution during the larval phase were also commercially harvested. One explanation offered by the authors was that a reduction of the stock biomass caused erosion of spatial structure in the form of lower spatial heterogeneity, potentially because of local depletion of subunits within a population. In turn, a stock with eroded spatial structure is more likely to show changes of its distribution simply because of reduced heterogeneity of spatial responses to environmental variation. Ultimately, the strong dependence of a stock on a single or few geographic locations may imperil the viability of the stock in the face of further harvest under environmental change.

We have a better appreciation of the consequences of loss of the spatial structure of sympatric discrete populations or demes within a metapopulation (e.g. McQuinn 1997, Hsieh et al. 2010, Perry et al. 2010) than we have for loss of structure within a panmictic population. However, there are several mechanisms by which an erosion of spatial structure can affect panmictic populations and community dynamics. For example, the sudden loss of local density hotspots may create a spatial mismatch between predator and prey species, where predators consistently exploit such areas for food. This in turn will affect predatorprey temporal dynamics and, where these food web links are important, impact the surrounding assemblages. Furthermore, spatial contractions with reduced abundance can also change the spatial overlap with predators (Kempf et al. 2008, Hunsicker et al. 2010,
Zador et al. 2011). With the selective removal of older individuals from the population or from certain locations, the remaining individuals may also lose the ability to 'learn' established migratory pathways (e.g. Corten 2001) or may be led to unsuitable habitats. For example, if repeat spawning at a site is imprinted and young fish learn where to spawn from older fish (social facilitation), then if the tested spawning location is suboptimal for survival, it will represent a population trap that attracts young fish from other spawning locations. The behavioral change required to modify such suboptimal spawning decisions may require several generations of failure before it is realized.

\section{EVIDENCE}

We provide evidence from the literature of changes in spatial structure and relative population and community dynamics. Attributing each case study to a population type has been challenging, a fact that underscores the complex nature of population genetic and demographic structures. Yet, grouping populations based on their spatial, demographic and genetic structures is a common practice in ecology (e.g. Pulliam 1988, Smedbol et al. 2002) and in this review has been instrumental to describe the genesis and maintenance of spatial structure and the consequences of its erosion. However, in nature, individuals are not aware of our theoretical boundaries and behave in ways that may challenge their premises (Thomas \& Kunin 1999). This does not invalidate the classification but rather underscores the need to recognize its limits when applied to wild populations. In the following case studies, the main intent of the grouping is to provide a general framework for understanding the consequences of spatial erosion across a wide range of genetically and demographically connected populations.

\section{Sympatric populations: Alaska walleye pollock} (Fig. 2)

Alaska pollock Theragra chalcogramma is North America's most abundant and lucrative fishery, representing $\sim 40 \%$ of the total US fisheries landings, with a gross annual value of over US\$ 1 billion (Ianelli et al. 2011). It is the world's largest human food fishery. Pollock is a gadid species, closely related to Atlantic cod, and often dominates the coastal ecosystems of the North Pacific Ocean. Pollock is 
usually considered a semi-demersal inhabitant of the continental shelf, but the species can occupy a wide range of habitats and environmental conditions, such as inshore seagrass beds, large estuaries, coastal embayments and offshore oceanic waters (Bailey et al. 1999). It is a subarctic species (Mueter \& Litzow $2008)$, living in water temperatures ranging from $1^{\circ}$ to $10^{\circ} \mathrm{C}$. Pollock reach maturity at 3 to $4 \mathrm{yr}$ of age, and individual females spawn millions of eggs each year (Hinckley 1987). There are several pollock spawning aggregations in the Alaska, USA, region (Fig. 2). Throughout the entire range of pollock distribution, there is good evidence of genetic separation at large scales, such as the eastern versus western Pacific or Alaska versus Puget Sound (Washington, USA) aggregations, and weaker evidence for separation at smaller scales within the Alaska region, such as between the Gulf of Alaska and the Bering Sea (Bailey et al. 1999). At even smaller scales, such as within the Gulf of Alaska or Bering Sea, the genetic structure is still unresolved, and the picture that emerges can vary with the use of different genetic markers (e.g. O'Reilly et al. 2004, Canino et al. 2005). How- ever, it is clear that the Alaskan pollock forms a complex population structure with sympatric reproductively isolated stocks at larger scales and with several degrees of mixing at smaller scales. It is possible that this picture may be more common than assumed in many management scenarios.

Pollock populations in the Alaska region provide comparisons of situations where climate change or overfishing, as well as synergism between the 2 forces, have caused a decline in spatial structure. At the northern end of the pollock stock, one major population existed in the Aleutian Basin of the central Bering Sea, although its relationship to adjacent shelf populations is still unresolved and controversial (Bailey 2011). In the early part of the 1980 s, population assessment models indicated a biomass of nearly 13 million $\mathrm{t}$ of pollock over age $5 \mathrm{yr}$ in the US zone of the central Bering Sea alone. Americanization of the fishery occurring in the US zone in the mid-1980s forced the substantial foreign fishery into the international Donut Hole zone (Bailey 2011). The highest reported annual catch from the Aleutian basin fisheries was 1.7 million $t$ in 1987, but it was likely higher than that

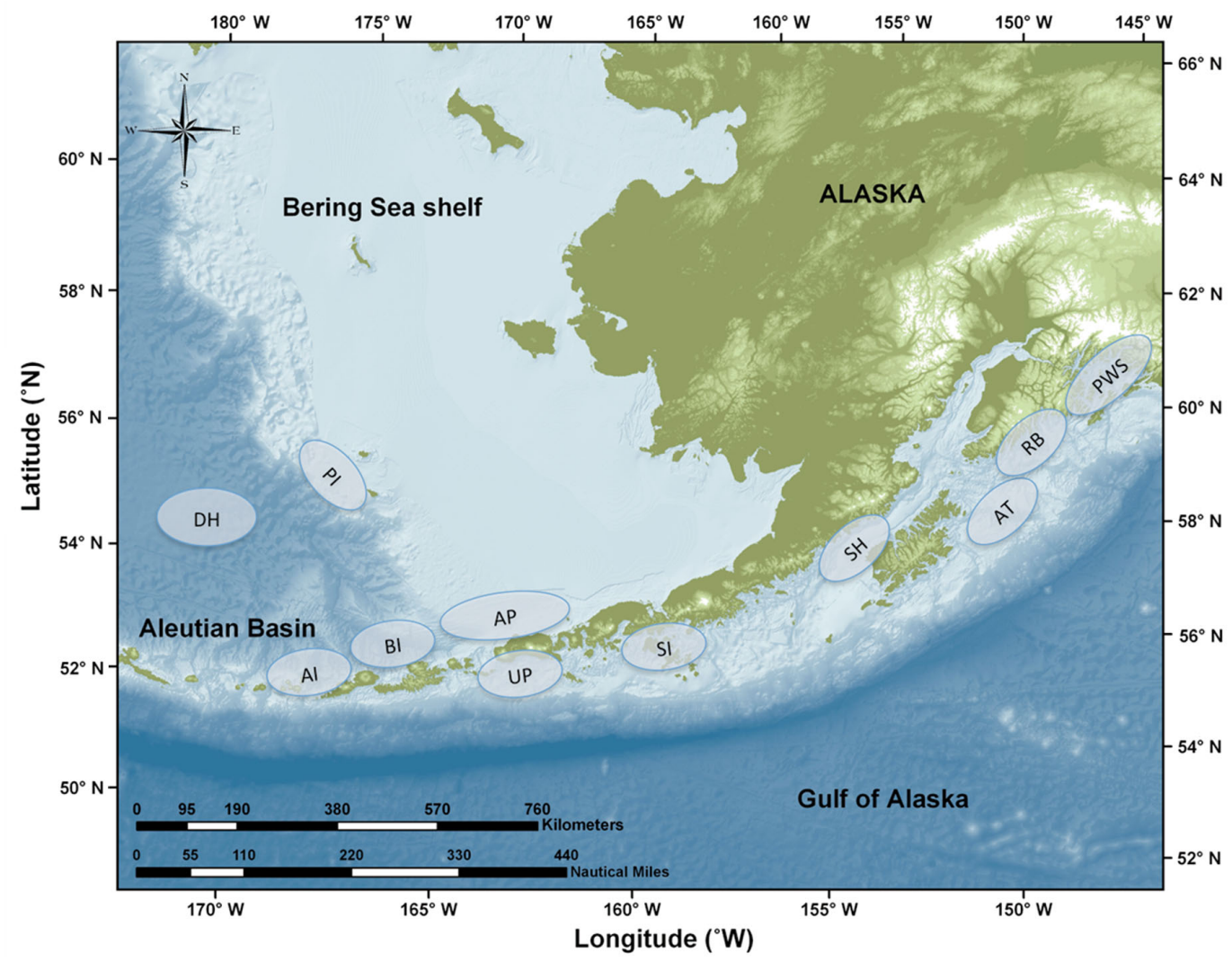

Fig. 2. Alaska, USA, region with known locations of walleye pollock Theragra chalcogramma spawning activity in the western Gulf of Alaska and eastern Bering Sea. The size of the location is not proportional to the spawning stock. PWS: Prince William Sound; RB: Resurrection Bay; AT: Amatuli Trough; SH: Shelikof Strait; SI: Shumagin Islands; UP: Unimak Pass; AP: Alaska Peninsula; BI: Bogoslof Island; AI: Aleutian Islands; DH: Donut Hole; PI: Pribilof Islands 
(Bailey 2011). Noticeably, the peak of the landings occurred when the decline of the population biomass was already underway. In 1988, the Aleutian Basin biomass plunged to $50 \%$ of its peak value and by 1992 was only $6 \%$ of the maximum. In 2007, the population was estimated at $309000 \mathrm{t}$, a drop of $98 \%$ from its peak. The Aleutian Basin population of pollock is currently commercially extinct. It has remained at this depleted level for 20 yr. This represents a depopulation covering $\sim 1$ million square miles. Because the fishery was so remote, the consequences to the ecosystem are unknown but could be substantial. There was no recognized trend in temperature or zooplankton abundance during the period of steep decline, so the major factor appears to be overfishing and poor recruitment (Bailey 2011). In recent years, the Pacific fur seal Callorhinus ursinus population of Bogoslof Island in the southeastern corner of the Aleutian Basin has been increasing at a dramatic pace. Pollock is usually an important component of the fur seal diet, but in this case they are eating mainly squid and deep-sea smelts. It is unknown whether these species have increased in abundance since the demise of pollock.

Still in the Bering Sea, but in the slope and shelf areas, there are several known pollock spawning aggregations (Bacheler et al. 2010) (Fig. 2). Collectively, the Bering Sea shelf and slope pollock have waxed and waned but remain reasonably abundant, and in fact, the commercial stock exhibited signs of a modest recovery in 2011 from a low point in 2008 to 2010. Changes in the spatial distribution of these populations have been linked to both abundance and climate (Bacheler et al. 2010). While the recruitment dynamics and stock size of pollock in the eastern Bering Sea remain fairly constant, this population has lost much of its spatial structure, especially during the larval and juvenile phase. For example, the once abundant larval aggregation around Bogoslof Island is much reduced in more recent years (Bacheler et al. 2010). Also, while juveniles (age $\geq 1$ yr) were mostly distributed throughout the shelf, they are mostly localized in the northwest portion of the shelf in more recent years. These facts provide some evidence of reduced spatial structure over different life history stages and should be taken as early warning for potential additional negative effects at the population level. Causes of concern for the pollock stocks in the region also arise from the continuous increase in abundance of arrowtooth flounder Atherestes stomias (a piscivorous flatfish), which has caused an expansion of its habitat (Ciannelli et al. 2012) and a greater overlap (Hunsicker et al. 2010) and predatory impact
(Zador et al. 2011) on its prey, the juvenile stage of walleye pollock, particularly in the northwest shelf region.

In the western Gulf of Alaska, potential overfishing and ecosystem reorganizations have caused changes in the spatial distribution of pollock. As in the Bering Sea, there are several recognized spawning populations of pollock in the Gulf of Alaska (Ciannelli et al. 2007b) (Fig. 2), mostly associated with deepwater bays or deep canyons and sea valleys intruding into the continental shelf. The largest population has historically been in the Shelikof Strait. This population was at a peak of 2.8 million $t$ in 1981 from acoustic estimates of biomass during the prespawning period. Catch rates peaked in 1984 at $307000 \mathrm{t}$ as the population was already in decline. In 2007, the biomass was reduced to $180000 \mathrm{t}$, and catches were $\sim 50000 \mathrm{t}$. Ciannelli et al. (2007b), analyzing egg distribution, showed that the spatial structure of the population had considerably decreased after the 1990s. The once conspicuous Shelikof Strait spawning aggregation is no longer dominant. Biomass levels of the population are now $\sim 10 \%$ of the maximum observed. Bacheler et al. (2009) showed that with a decreased spawning biomass, spawning areas (as detected by egg density) were also reduced. As a result of the declines in this local concentration and other factors, such as management strategies to spread fishing effort and thus protect local Steller sea lions Eumetopias jubatus, the commercial fishery has shifted to the harvest of other smaller local populations, including those off Sanak and the Shumagin Islands. There has been considerable controversy about the effects of the pollock depletion on marine mammal and seabird populations, with the greatest concern for its effect on the endangered Steller sea lion. This issue remains unresolved.

\section{Metapopulation: eastern Scotian Shelf cod}

(Figs. 3 \& 4)

Cod resident on the eastern Scotian Shelf supported an important commercial fishery with average landings close to $50000 \mathrm{t}$ during the $1970 \mathrm{~s}$ and 1980s (Fig. 3). Mobile gear fisheries, specifically otter trawling, typically accounted for $70 \%$ of the catch. Landings peaked in the mid 1980s, when the biomass had already started its decline. Annual instantaneous fishing mortality increased monotonically from $\sim 0.2$ in the late 1970s to 1.6 in 1992, the year before the population collapsed (Frank et al. 1994). Distribution patterns of adult cod prior to collapse were wide- 


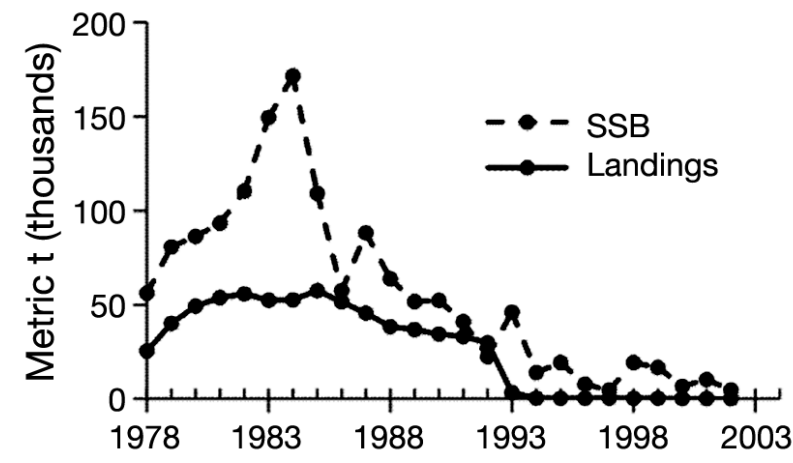

Fig. 3. Gadus morhua. Spawning stock biomass (SSB) and landings of the eastern Scotian Shelf cod (DFO 2011) spread with major concentrations on most of the offshore banks along the shelf edge and Laurentian channel (Fig. 4A). After the collapse (Fig. 4B), nearly all of the banks were devoid of cod, and the few remaining concentrations were being protected by a moratorium on directed fishing for cod that was established in September of 1993. The moratorium remains in effect at present, and recovery has been very slow.

In addition to the spatial constriction, there has been a reduction in the temporal structure of spawning. Historically, the offshore banks were areas where spawning occurred during both spring and fall.
A
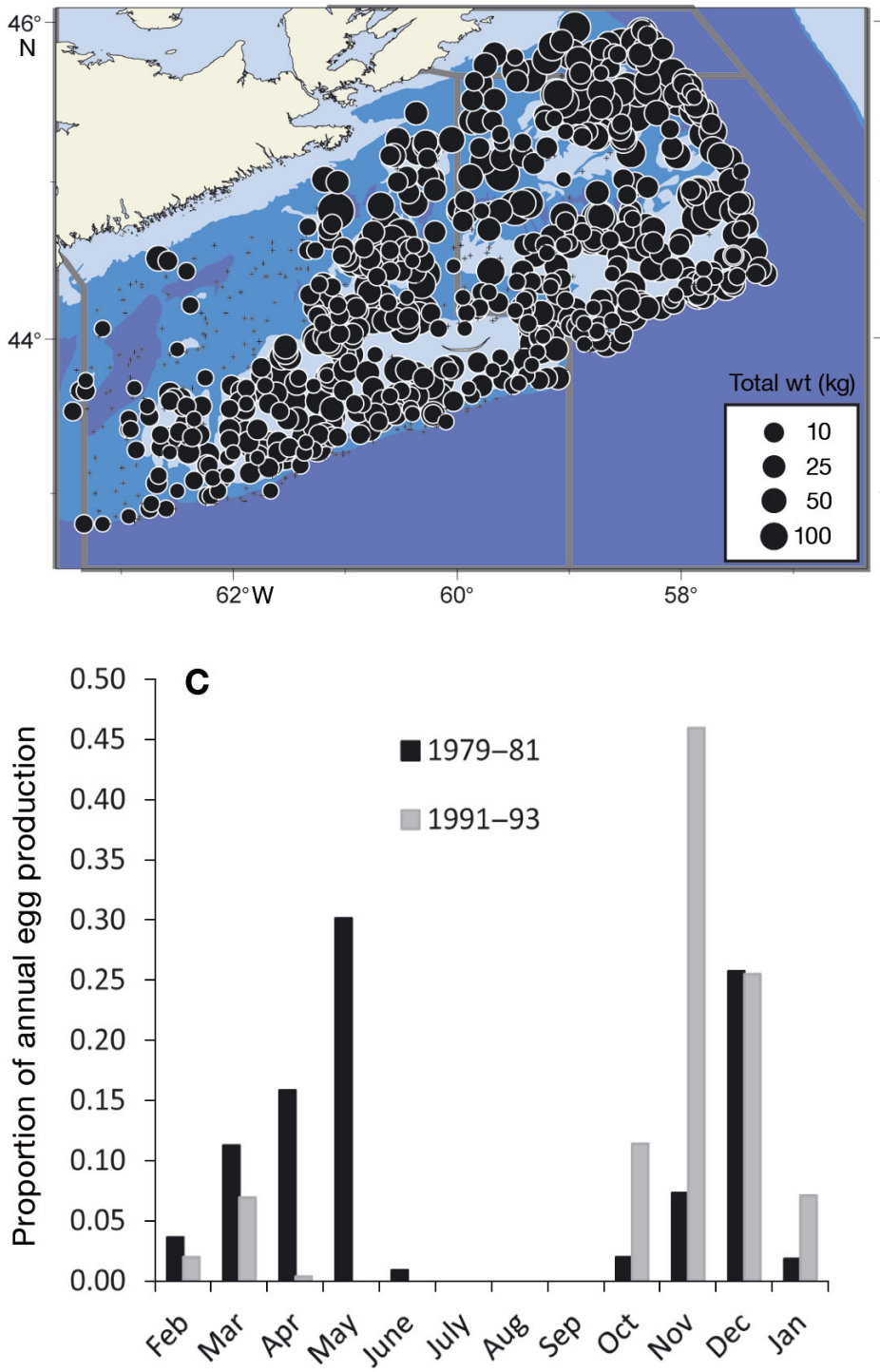

B
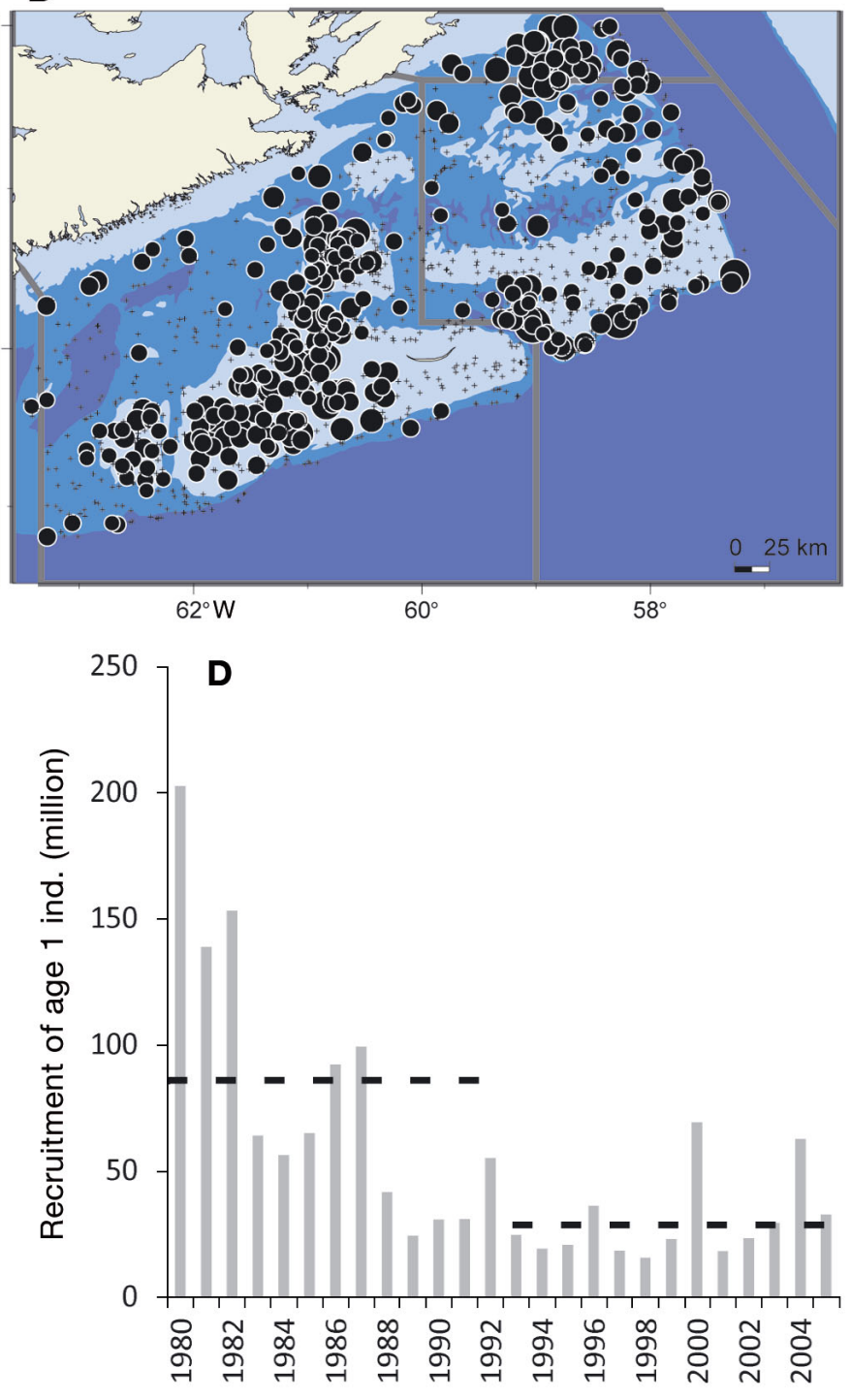

Fig. 4. Eastern Scotian Shelf cod Gadus morhua. Spatial distribution patterns of adult cod (A) before and (B) after the collapse in 1993. Proportion of cod eggs by month on the eastern Scotian Shelf from (C) 1979 to 1981 and 1991 to 1993 and (D) cod recruitment at age 1 yr. Grey lines in (A) and (B) show the boundaries of the Northwest Atlantic Fishery Organization. Horizontal dashed lines in (D) show the average recruitment during the pre- and post-collapse periods 
Fig. 4C shows the proportion of cod eggs by month on the eastern Scotian Shelf from 1979 to 1981 and from 1991 to 1993. Distinct bi-modality was evident in the earlier period, while the spring (May to June) production was virtually absent in the latter period (Miller et al. 1995). This was one of the earliest indications of the erosion of population structure. The loss of the spring component was considered to have had a major impact on population renewal, given the capacity of the spring bloom and following events to generate new recruits in this and virtually all other temperate marine ecosystems. The loss of the spring spawning component as well as the overall reduction in spawning stock biomass were associated with a dramatic decline in annual recruitment (Fig. 4D).

Historically, and on a larger scale, cod recruitment in the Northwest Atlantic was synchronous at scales in excess of $500 \mathrm{~km}$ due, in part, to dispersal among adjacent stocks. Coincident with the cod collapse was a halving of the spatial scale of recruitment synchrony, suggesting an erosion of inter-stock connectivity and a further limitation to local recovery by reducing the probability of immigration from neighboring stocks (Kelly et al. 2009), i.e. the rescue effect. The collapse of cod on the eastern Scotian Shelf resulted in substantial changes in the composition of the fishery as several fisheries were newly created and some existing fisheries became extremely profitable. For example, as the percentage contribution of groundfish to the total landed value steadily declined from $>70$ to $<10 \%$ from the 1980 s to the early 2000s, invertebrate fisheries (mainly snow crab and shrimp) rose from 12 to $85 \%$ (DFO 2003). Ironically, the cod collapse produced a new fishery regime in which the inflation-adjusted monetary value of the combined shrimp and crab landing alone far exceeded that of the groundfish fishery it replaced. From an economic perspective, this may be a more attractive situation, but one cannot ignore the ecological risks of fishing down the food chain and the possibility that a focused fishery on the prey of the former groundfish could further impede recovery.

\section{Panmictic population: Norwegian spring spawning herring (Figs. 5 \& 6)}

The Norwegian spring spawning (NSS) herring is a long-lived, pelagic fish with historic maximum stock levels at 15 to 20 million $t$ and has in periods been the most important fish resource in the Northeast Atlantic (Hamre 1990). Unlike other case studies that we review in the present article, the NSS is a success story due to the spectacular recovery of both demographic and spatial structures following a collapse. The NSS is also a fascinating case study because it elucidates how human harvest and environmental variability interact with internal behavioral mechanisms to affect migratory pathways and the overall spatial structure and occupancy of a panmictic population.

Between 1 and 2 million t were landed annually in the 1950s and 1960s (Nakken 2008). The peak of the catch occurred in the late 1960s, when the biomass decline was already underway (Fig. 5). NSS herring have a complex spatial ecology, including distribution shifts with ontogenetic shifts and extensive and variable seasonal migrations as adults. The NSS herring spawn in spring along the Norwegian coast. The larvae drift with currents into nursery areas along the coast and into the Barents Sea, where they remain until $\sim 4$ yr of age. Thereafter, young herring migrate to the Norwegian Sea and take part in summer foraging, winter and spring spawning migrations. However, the areas used for spawning, foraging and wintering have varied considerably over the last decades (Dragesund et al. 2008) (Fig. 6). Due to the spatial complexity of herring stocks, the proposed population structures have ranged from discrete populations associated with the different spawning areas to a spatially complex panmictic population for which the structure, persistence and dynamics are best explained by behavioral rather than genetic mechanisms (Slotte \& Fiksen 2000 and references therein). More recent studies support the latter stock structure and the hypothesis that behavioral and densitydependent mechanisms play a dominant role in de-

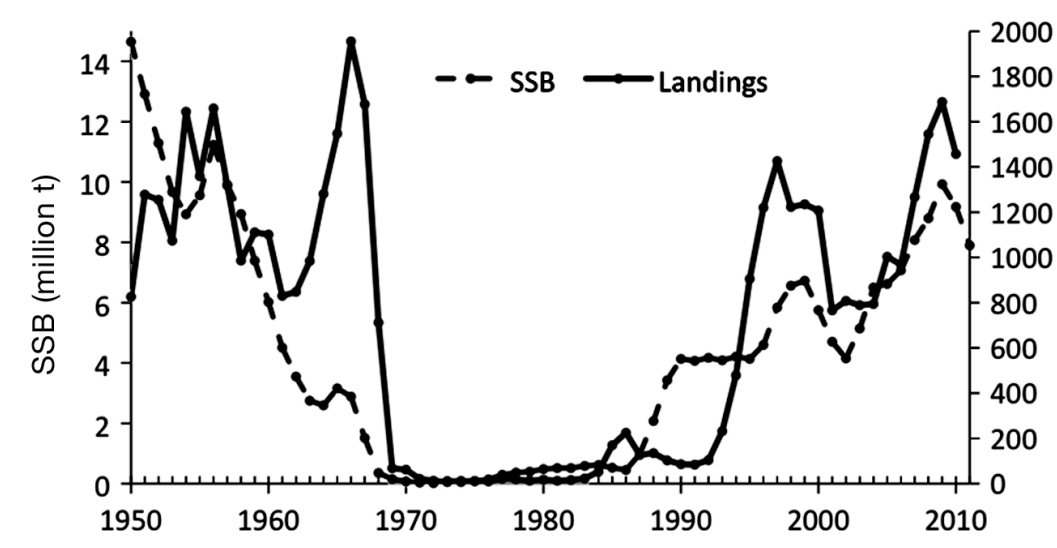

Fig. 5. Clupea harengus. Spawning stock biomass (SSB) and landings of Norwegian spring spawning herring (ICES 2011) 

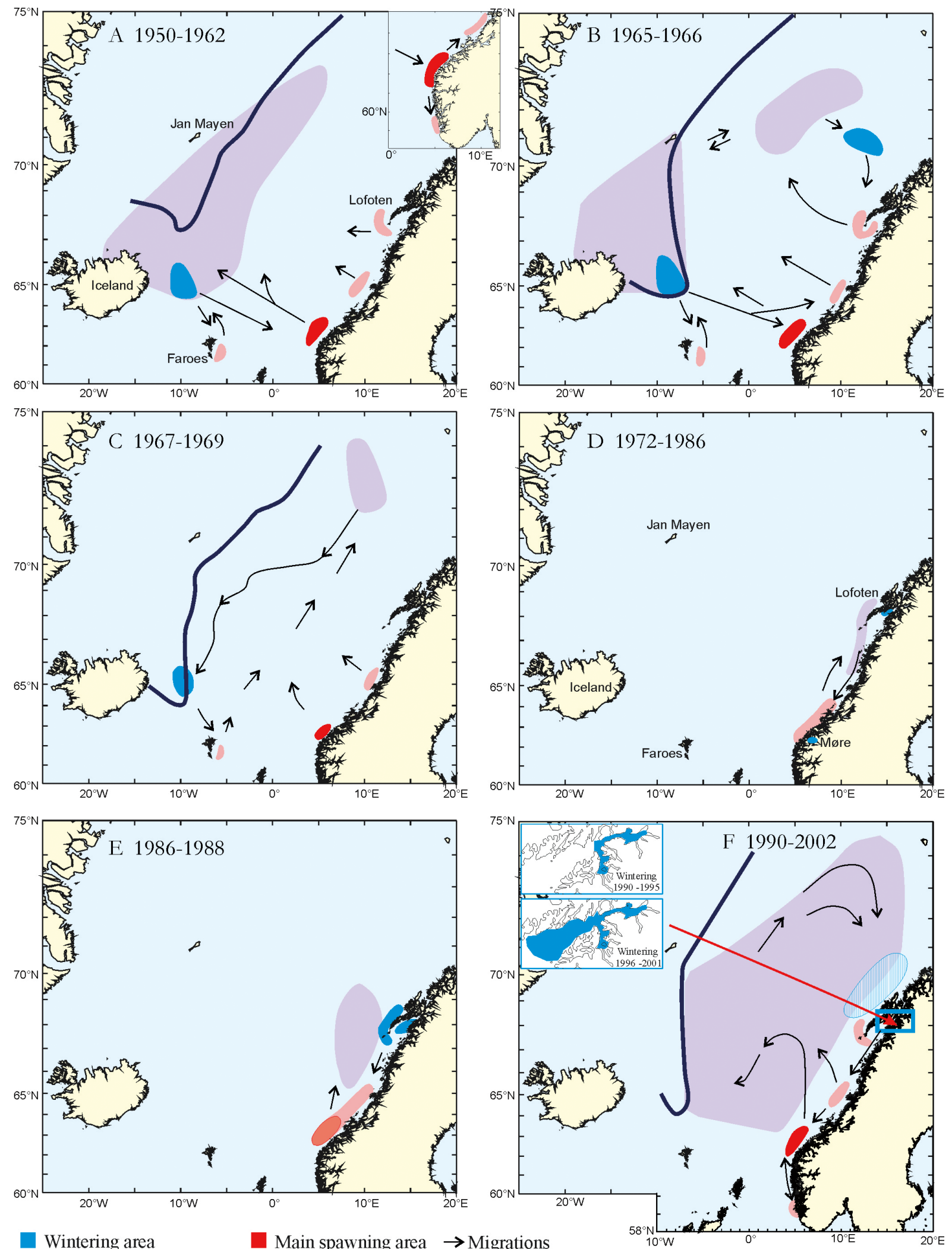

Wintering area

Possible new additional wintering area from 2002

Main spawning area $\rightarrow$ Migrations

I $2^{\circ}$ isotherm at $50 \mathrm{~m}$

Spawning area

Feeding area depth

Fig. 6. Clupea harengus. Main migration patterns of the Norwegian spring spawning herring from 1950 to 2003 . From Holst et al. (2004), with permission 
termining the spatial structure of the NSS herring (e.g. Slotte \& Fiksen 2000, Huse et al. 2010).

After 2 decades of rapid population decline, the NSS herring collapsed around 1970 due to high fishing mortality and adverse environmental conditions negatively impacting recruitment (Toresen \& Østvedt 2000, Dragesund et al. 2008) (Fig. 5). Prior to the decline, spawning occurred from northern to southwestern Norway (Fig. 6A,B). The summer feeding migrations were long and directed toward the polar front in the Iceland and Jan Mayen areas. Wintering areas were mainly east of Iceland. During the population decline, the geographic range of the spawning areas shrunk, and no spawning occurred in the northern areas (Fig. 6C). The summer feeding areas shifted north and eastward toward the Norwegian coast. By the time of the collapse, the oceanic feeding migrations had ceased, and the summer feeding occurred only along the Norwegian coast (Fig. 6C). The herring also vacated the traditional wintering areas and started wintering along the Norwegian coast. Thus, after the collapse, the herring remained in coastal waters all year (Fig. 6D).

The changes in both spawning and feeding migrations appear to have been density-dependent, although unfavorable environmental conditions may also have had some influence (Slotte \& Fiksen 2000, Holst et al. 2004). At lower densities, herring are generally in better condition and perform longer spawning migrations to southern spawning habitats (Slotte \& Fiksen 2000). These habitats likely have favorable physical conditions that promote growth and survival of the fry (Slotte \& Fiksen 2000). In contrast, at high abundances, the feeding migrations are longer, likely propelled by prey depletion (Holst et al. 2004). Following the collapse, the few remaining herring had likely met their energetic requirements in the coastal areas. Thus, in the NSS herring, reduced migration distances and costs, improved condition and an increasing use of optimal spawning habitats are parts of spatial processes that could positively influence recruitment at low stock abundances. However, the recruitment in NSS herring is highly variable and poorly understood, and reduced population-level resilience by spatial contraction of spawning distribution has also been discussed for this species (Dragesund et al. 2008).

The changes in wintering areas, however, are likely linked to behavioral mechanisms. Herring remain in wintering areas in dense concentrations for $\sim 5$ mo without feeding. Also, the coastal wintering areas have varied considerably during the last decades. Huse et al. (2010) demonstrated that each shift in wintering areas has been associated with a new and strong year class entering the spawning stock. Huse et al. (2010) suggested that there is a cultural transfer of the use of wintering areas, which breaks down when the proportion of recruits is high relative to that of older herring, resulting in establishment of new wintering areas.

In the 1970 s, the herring fisheries were strictly regulated, and $<20000 \mathrm{t}$ were landed each year (Fig. 5). However, due to the spatial contraction of herring in coastal areas during spawning, feeding and wintering, the fishermen found herring on the coast all year round, occasionally at high densities. This resulted in strong disagreements between scientists and fishermen concerning the state of the herring stock and how much could be harvested (Dragesund et al. 2008). Until the late 1970 s, the technical equipment and the efficiency of the herring fisheries had developed more rapidly than the stock assessment tools available for the scientists. However, in 1979, an abundance estimate for the spawning stock was produced, revealing that the stock was at a very low level, and the strict regulations continued (Dragesund et al. 2008).

The herring started recovering in the late 1980s. The stock is currently at 9 million $t$ and is considered to be fully recovered, although a reduction in abundance has been observed in recent years (Fig. 5). Weak recruitment since 2004 and reduction of older, abundant cohorts due to fishing and natural mortality is causing the stock decline. However, the westward, oceanic feeding migrations have resumed, spawning distributions have expanded northward (Fig. 6E,F), and the wintering areas have shifted westward from the inner fjords to off the shelf. Thus, the herring appears to have been fully able to recolonize historically used areas and habitats.

\section{CONSERVATION}

Although species are adapted to the natural variability of the environment that they inhabit, the effects of fishing and climate on the erosion of population structure interact and are at times synergistic. For instance, fishing impacts the geographic extent of a population as well as the demographic structure (e.g. truncated age/size classes) and thereby weakens the remaining population's capacity to buffer the effects of unfavorable environmental conditions (Perry et al. 2010, Planque et al. 2010). Also, climateinduced spatial contractions or merging of exploited fish stocks can lead to increases in local fish densities 
and catchability, which in turn make stocks more vulnerable to overfishing (Atkinson et al. 1997, Rose et al. 2000). These effects are very dependent on the life history adaptations that species or stocks have evolved to deal with environmental variability, predation pressure and ontogenetic division of prey resources. The link between climate- and fishinginduced changes of population structure and the ensuing effects on species abundance calls for a more integrated approach to the study of fish spatial distributions, one that takes into account human and environmental drivers. It also calls for a more comprehensive management approach, in which the spatial structure of a population is monitored and catches are numerically and also geographically accounted for (Link et al. 2011).

It is interesting that there is the fractal view of lumpers and splitters in both species differentiation and in population structure. We realize that our own classification of the 3 case studies to a specific population type (Table 1) may draw counter-opinions. We wish there was a way to unequivocally distinguish the demographic and genetic structure of populations, but the results to date only point to the controversial nature of these classifications. However, we contend that this controversy is counterproductive and hampers the establishment of management frameworks that integrate population structures. Genetic techniques may provide blurred pictures of the degree of separation between different subgroups in a population. Similarly, non-genetic techniques, such as otolith microchemistry, may give conflicting results (Secor 2010). Does that mean that populations are not structured or that some level of structure should not be considered in management?

Our review was motivated by 2 simple questions, namely (1) Is a change of population spatial structure a mere manifestation of removing individuals from a population, or is it also a prelude to further changes in population abundance? and (2) Is the spatial structure of fish populations that are commercially harvested an attribute that is worth monitoring and preserving? Throughout our review, we have shown how populations can be spatially structured, regardless of their genetic and demographic connections. It is also important to note that in the 3 case studies examined here, the landings peaked several years after a declining trend of abundance commenced (Figs. 3 \& 5) (Bailey 2011, DFO 2011). Of course, it is simple to unveil these temporal discrepancies between harvest and abundance trends when many years have gone by and population abundance estimates have improved with retrospection. Similar downward population trends may have not been apparent at the time the trend started. However, what we have learned from hindsight highlights the fact that biomass and recruitment estimates alone are not good predictors of future population trends and underscores the importance of supplementing management with additional spatial indices of population status. We have also reviewed cases in which the erosion of this spatial structure is a prelude to further changes of population abundance for reasons that go beyond, and are more long lasting, than the removal of individuals from a location. Therefore, the monitoring and preservation of a population's spatial structure should be an explicit management goal. The upside is that in marine populations, spatial structures are easier to monitor and characterize (e.g. Woillez et al. 2007) than demographic and genetic structures. Many commercially exploited stocks are surveyed often multiple times in a year and over different life history stages. There is already a large body of available information that can be integrated in management scenarios and that is less controversial than other metrics of population structures.

Acknowledgements. We thank the Research Council of Norway for funding the workshop Tropharct through the MICO project (number 186310, Match/Mismatch and Ecosystem). L.C. and M.H. acknowledge support from the National Science Foundation - Research Coordination Network grant number 1140207. M.S.M. acknowledges support from grant number 20049/130 of the Norwegian Research Council's 'Adaptive management of living marine resources by integrating different data sources and key ecological processes (ADMAR)' program. We are indebted to J. Hutchings and P. Spencer, who reviewed earlier versions of this article, and to 4 anonymous reviewers, who provided insightful comments. Finally, we thank C. Vestfals, who is the author of Fig. 2.

\section{LITERATURE CITED}

Atkinson DB, Rose GA, Murphy EF, Bishop CA (1997) Distribution changes and abundance of northern cod (Gadus morhua), 1981-1993. Can J Fish Aquat Sci 54:132-138

Bacheler NM, Bailey KM, Ciannelli L, Bartolino V, Chan KS (2009) Density-dependent, landscape, and climate effects on spawning distribution of walleye pollock Theragra chalcogramma. Mar Ecol Prog Ser 391:1-12

Bacheler NM, Ciannelli L, Bailey KM, Duffy-Anderson JT (2010) Spatial and temporal patterns of walleye pollock spawning in the eastern Bering Sea inferred from egg and larval distributions. Fish Oceanogr 19:107-120

Bailey KM (2011) An empty donut hole: the great collapse of a North American fishery. Ecol Soc 16:28

> Bailey KM, Quinn T, Grant WS, Bentzen P (1999) Population structure and dynamics of walleye pollock, Theragra chalcogramma. Adv Mar Biol 37:179-255

Bailey KM, Abookire A, Duffy-Anderson JT (2008) Ocean transport paths for the early life stages of offshore- 
spawning flatfishes: a case study in the Gulf of Alaska. Fish Fish 9:44-66

> Bartolino V, Ciannelli L, Spencer P, Wildebauer T, Chan KS (2012) Scale-dependent detection of the effects of harvesting a marine fish population. Mar Ecol Prog Ser 444: 251-272

Berryman A (2002) Populations: a central concept for ecology? Oikos 97:439-442

Betts MG, Forbes GJ, Diamond AW, Taylor PD (2006) Independent effects of fragmentation on forest songbirds: an organism-based approach. Ecol Appl 16:1076-1089

Borregaard MK, Rahbek C (2010) Causality of the relationship between geographic distribution and species abundance. Q Rev Biol 85:3-25

Brander K (2010) Impacts of climate change on fisheries. J Mar Syst 79:389-402

Brander K, Botsford L, Ciannelli L, Fogarty $M$ and others (2010) Human impacts on marine ecosystems. In: Barange $M$, Field JG, Harris RP, Hofmann EE, Perry IR, Werner F (eds) Marine ecosystems and global change. Oxford University Press, New York, NY, p 41-72

> Brown JH, Mehlman DW, Stevens GC (1995) Spatial variation in abundance. Ecology 76:2028-2043

Cadrin SX, Secor DH (2009) Accounting for spatial population structure in stock assessment: past, present, and future. In: Beamish RJ, Rothschild BJ (eds) The future of fisheries science in North America. Springer, Dordrecht, p 405-426

Canino MF, O'Reilly PT, Hauser L, Bentzen P (2005) Genetic differentiation in walleye pollock (Theragra chalcogramma) in response to selection at the pantophysin (PanI) locus. Can J Fish Aquat Sci 62:2519-2529

> Cheung WWL, Lam VWY, Sarmiento JL, Kearney K, Watson R, Zeller D, Pauly D (2010) Large-scale redistribution of maximum fisheries catch potential in the global ocean under climate change. Glob Change Biol 16:24-35

> Ciannelli L, Dingsør G, Bogstad B, Ottersen G and others (2007a) Spatial anatomy of species survival rates: effects of predation and climate-driven environmental variability. Ecology 88:635-646

> Ciannelli L, Bailey K, Chan KS, Stenseth NC (2007b) Phenological and geographical patterns of walleye pollock spawning in the Gulf of Alaska. Can J Fish Aquat Sci 64:713-722

> Ciannelli L, Fauchald P, Chan KS, Agostini VN, Dingsør GE (2008) Spatial fisheries ecology: recent progress and future prospects. J Mar Syst 71:223-236

> Ciannelli L, Knutsen H, Moland E, Espeland SH and others (2010) Small-scale genetic structure in a marine population in relation to water circulation and egg characteristics. Ecology 91:2918-2930

- Ciannelli L, Bartolino V, Chan KS (2012) Nonadditive and nonstationary properties in the spatial distribution of a large marine fish population. Proc R Soc Lond B 279: 3635-3642

> Corten A (2001) The role of 'conservatism' in herring migrations. Rev Fish Biol Fish 11:339-361

> Cury P (1994) Obstinate nature: an ecology of individuals. Thoughts on reproductive behavior and biodiversity. Can J Fish Aquat Sci 51:1664-1673

DFO (Canadian Department of Fisheries and Oceans) (2011) Recovery potential assessment for the Laurentian South designatable unit of Atlantic cod (Gadus morhua). DFO Can Sci Advis Sec Sci Advis Rep 2011/028, DFO, Ottawa Dragesund O, Østvedt OJ, Toresen R (2008) Norwegian spring spawning herring: history of fisheries, biology and stock assessment. In: Nakken O (ed) Norwegian spring spawning herring and northeast arctic cod. Tapir Academic Press, Trondheim, p 41-82

Duffy-Anderson J, Blood DM, Cheng W, Ciannelli L and others (2013) Combining field observations and modeling approaches to examine Greenland halibut (Reinhardtius hippoglossoides) early life ecology in the southeastern Bering Sea. J Sea Res 75:96-109

Dunning JB, Danielson BJ, Pulliam RH (1992) Ecological processes that affect populations in complex landscapes. Oikos 65:169-175

Eby LA, Crowder LB, McClellan CM, Peterson CH, Powers MJ (2005) Habitat degradation from intermittent hypoxia: impacts on demersal fishes. Mar Ecol Prog Ser 291:249-262

Fabry VJ, Seibel BA, Feely RA, Orr JC (2008) Impacts of ocean acidification on marine fauna and ecosystem processes. ICES J Mar Sci 65:414-432

Fauchald P, Erikstad KE, Skarsfjord H (2000) Scaledependent predator-prey interactions: the hierarchical spatial distribution of seabirds and prey. Ecology 81: 773-783

Fauchald P, Mauritzen M, Gjosaeter H (2006) Densitydependent migratory waves in the marine pelagic ecosystem. Ecology 87:2915-2924

Fisher JAD, Frank KT (2004) Abundance-distribution relationships and conservation of exploited marine fishes. Mar Ecol Prog Ser 279:201-213

Frank KT, Drinkwater KF, Page FH (1994) Possible causes of recent trends and fluctuations in Scotian Shelf/Gulf of Maine cod stocks. ICES Mar Sci Symp 198:110-120

Frank KT, Petrie B, Shackell NL (2007) The ups and downs of trophic control in continental shelf ecosystems. Trends Ecol Evol 22:236-242

> Fretwell SD, Lucas HL (1969) On territorial behavior and other factors influencing habitat distributions in birds. I. Theoretical development. Acta Biotheor 19:16-36

Gaston KJ, Blackburn TM, Greenwood JJD, Gregory RD, Quinn RM, Lawton JH (2000) Abundance-occupancy relationships. J Appl Ecol 37(Suppl 1):39-59

> Gonzalez A, Lawton JH, Gilbert FS, Blackburn TM, EvansFreke I (1998) Metapopulation dynamics, abundance, and distribution in a microecosystem. Science 281: 2045-2047

Goodwin BJ, Fahrig L (1998) Spatial scaling and animal population dynamics. In: Peterson DL, Parker VT (eds) Ecological scale: theory and applications. Columbia University Press New York, NY, p 193-206

Hamre J (1990) Life history and exploitation of the Norwegian spring spawning herring. Section I. In: Monstad T (ed) Biology and fisheries of the Norwegian springspawning herring and blue whiting in the northeast Atlantic. Proc 4th Soviet-Norwegian Symp, Bergen, 12-16 June 1989. Institute of Marine Research, Bergen, p 5-39

Hauser L, Carvalho GR (2008) Paradigm shifts in marine fisheries genetics: ugly hypotheses slain by beautiful facts. Fish Fish 9:333-362

> Heath MR, Kunzlik PA, Gallego A, Holmes SJ, Wright PJ (2008) A model of meta-population dynamics for North Sea and West of Scotland cod-the dynamic consequences of natal fidelity. Fish Res 93:92-116

Hilborn R, Quinn TP, Schindler DE, Rogers DE (2003) Biocomplexity and fisheries sustainability. Proc Natl Acad 
Sci USA 100:6564-6568

Hinckley S (1987) The reproductive biology of walleye pollock, Theragra chalcogramma, in the Bering Sea, with reference to spawning stock structure. Fish Bull 85: 481-498

Holst JC, Røttingen I, Melle W (2004) The herring. In: Skjoldal HR (ed) The Norwegian Sea ecosystem. Tapir Academic Press, Trondheim, p 203-226

Hsieh CH, Reiss SC, Hewitt RP, Sugihara G (2008) Spatial analysis shows fishing enhances the climatic sensitivity of marine fishes. Can J Fish Aquat Sci 65:947-961

> Hsieh CH, Yamauchi A, Nakazawa T, Wang WF (2010) Fishing effects on age and spatial structures undermine population stability of fishes. Aquat Sci 72:165-178

Hunsicker ME, Ciannelli L, Bailey KM, Zador S (2010) Processes driving differences in major food web linkages of the Gulf of Alaska and eastern Bering Sea ecosystems. ICES Annu Sci Conf 2010, Nantes

Huse G, Fernö A, Holst JC (2010) Establishment of new wintering areas in herring co-occurs with peaks in the 'first time/repeat spawner' ratio. Mar Ecol Prog Ser 409: 189-198

- Hutchings JA (2000) Collapse and recovery of marine fishes. Nature 406:882-885

> Hutchings JA, Swain DP, Rowe S, Eddinton JD, Puvanendran V, Brown JA (2007) Genetic variations in life-history reaction norms in a marine fish. Proc Biol Sci 274:1 693-1699

Ianelli JN, Barbeaux S, Honkalehto T, Kotwicki S, Aydin K, Williamson N (2011) Assessment of the walleye pollock stock in the eastern Bering Sea. Alaska Fisheries Science Center, National Marine Fisheries Services Seattle, WA

ICES (2011) Report of the Working Group on Widely Distributed Stocks (WGWIDE). ICES CM 2011/ACOM:15. ICES, Copenhagen

Iles TD, Sinclair M (1982) Atlantic herring: stock discreteness and abundance. Science 215:627-633

> Jones GP, Milicich MJ, Emslie MJ, Lunow C (1999) Selfrecruitment in a coral reef fish population. Nature 402 : 802-804

Kelly JE, Frank KT, Leggett WC (2009) Degraded recruitment synchrony in Northwest Atlantic cod stocks. Mar Ecol Prog Ser 393:131-146

Kempf A, Floeter J, Temming A (2008) Predator-prey overlap induced Holling type III functional response in the North Sea fish assemblage. Mar Ecol Prog Ser 367: 295-308

Knutsen H, Olse EM, Jorde PE, Espeland SH, Andre C, Stenseth NC (2011) Are low but statistically significant levels of genetic differentiation in marine fishes 'biologically meaningful'? A case study of coastal Atlantic cod. Mol Ecol 20:768-783

> Kokko H, Lopez-Sepulcre A (2006) From individual dispersal to species ranges: perspectives for a changing world. Science 313:789-791

> Köster FW, Möllmann C, Hinrichsen HH, Tomkiewicz J and others (2005) Baltic cod recruitment-the impact of climate and species interaction. ICES J Mar Sci 62: 1408-1425

> Lawton JH (1993) Range, population abundance and conservation. Trends Ecol Evol 8:409-413

> Levin SA (1992) The problem of pattern and scale in ecology. Ecology 73:1943-1967

Link JS, Nye JA, Hare JA (2011) Guidelines for incorporating fish distribution shifts into a fisheries management context. Fish Fish 12:461-469

> Litzow MA, Ciannelli L (2007) Oscillating trophic control induces community reorganization in a marine ecosystem. Ecol Lett 10:1124-1134

MacCall AD (1990) Dynamic geography of marine fish populations. University of Washington Press, Seattle, WA

McFarlane GA, Smith PE, Baumgartner TR, Hunter JR (2002) Climate variability and Pacific sardine populations and fisheries. Am Fish Soc Symp 32:195-214

> McQuinn IH (1997) Metapopulations and the Atlantic herring. Rev Fish Biol Fish 7:297-329

> Miller TJ, Herra T, Leggett WC (1995) An individual-based analysis of the variability of eggs and their newly hatched larvae of Atlantic cod (Gadus morhua) on the Scotian Shelf. Can J Fish Aquat Sci 52:1083-1093

Mueter FJ, Litzow MA (2008) Sea ice retreat alters the biogeography of the Bering Sea continental shelf. Ecol Appl 18:309-320

Murawski SA (2010) Rebuilding depleted fish stocks: the good, the bad, and, mostly, the ugly. ICES J Mar Sci 67 : 1830-1840

Nakken O (2008) Introduction. In: Nakken O (ed) Norwegian spring spawning herring and northeast arctic cod. Tapir Academic Press, Trondheim, p 9-16

Nøttestad L, Giske J, Holst JC, Huse G (1999) A lengthbased hypothesis for feeding migrations in pelagic fish. Can J Fish Aquat Sci 56:26-34

> Nye JA, Link JS, Hare JA, Overholtz WJ (2009) Changing spatial distribution of fish stocks in relation to climate and population size on the Northeast United States continental shelf. Mar Ecol Prog Ser 393:111-129

- O'Reilly PT, Canino MF, Bailey KM, Bentzen P (2004) Inverse relationship between $F_{\mathrm{ST}}$ and microsatellite polymorphism in the marine fish, walleye pollock (Theragra chalcogramma): implications for resolving weak population structure. Mol Ecol 13:1799-1814

> Olsen EM, Knutsen H, Gjøsæter J, Jorde PE, Knutsen JA, Stenseth NC (2008) Small-scale biocomplexity in coastal Atlantic cod supporting a Darwinian perspective on fisheries management. Evol Appl 1:524-533

Palumbi S (2003) Population genetics, demographic connectivity, and the design of marine reserves. Ecol Appl 13: 146-158

Perry AL, Low PJ, Ellis JR, Reynolds JD (2005) Climate change and distribution shifts in marine fishes. Science 308:1912-1915

> Perry RI, Cury P, Brander K, Jennings S, Mollmann C, Planque B (2010) Sensitivity of marine systems to climate and fishing: concepts, issues and management responses. J Mar Syst 79:427-435

> Planque B, Fromentin JM, Cury P, Drinkwater KF, Jennings S, Perry RI, Kifani S (2010) How does fishing alter marine populations and ecosystems sensitivity to climate? J Mar Syst 79:403-417

> Planque B, Loots C, Petitgas P, Lindstrom U, Vaz S (2011) Understanding what controls the spatial distribution of fish populations using a multi-model approach. Fish Oceanogr 20:1-17

Pulliam HR (1988) Sources, sinks, and population regulation. Am Nat 132:652-661

> Reiss H, Hoarau G, Dickey-Collas M, Wolff WJ (2009) Genetic population structure of marine fish: mismatch between biological and fisheries management units. Fish Fish 10:361-395

Rose GA, deYoung B, Kulka DW, Goddard SV, Fletcher GL 
(2000) Distribution shifts and overfishing the northern cod (Gadus morhua): a view from the ocean. Can J Fish Aquat Sci 57:644-663

Rowe S, Hutchings JA (2003) Mating systems and the conservation of commercially exploited marine fish. Trends Ecol Evol 18:567-572

Schindler DE, Hilborn R, Chasco B, Boatright CP, Quinn TP, Rogers LA, Webster MS (2010) Population diversity and the portfolio effect in an exploited species. Nature 465: 609-612

Secor DH (2010) Is otolith science transformative? New views on fish migration. Environ Biol Fishes 89:209-220

Shackell NL, Frank KT, Brickman DW (2005) Range contraction may not always predict core areas: an example from marine fish. Ecol Appl 15:1440-1449

Shepherd TD, Litvak MK (2004) Density-dependent habitat selection and the ideal free distribution in marine fish spatial dynamics: considerations and cautions. Fish Fish 5:141-152

Slotte A, Fiksen Ø (2000) State-dependent spawning migration in Norwegian spring-spawning herring. J Fish Biol 56:138-162

Smedbol RK, McPherson A, Hansen MM, Kenchington E (2002) Myths and moderation in marine 'metapopulations'. Fish Fish 3:20-35

Swain DP (1999) Changes in the distribution of Atlantic cod (Gadus morhua) in the southern Gulf of St. Lawrence-

Submitted: April 27, 2012; Accepted: September 21, 2012 effects of environmental change or change in environmental preferences? Fish Oceanogr 8:1-17

- Thomas CD, Kunin WE (1999) The spatial structure of populations. J Anim Ecol 68:647-657

Toresen R, Østvedt J (2000) Variation in abundance of Norwegian spring-spawning herring (Clupea harengus, Clupeidae) throughout the 20th century and the influence of climatic fluctuations. Fish Fish 1:231-256

Voss R, Hinrichsen HH, Stepputtis D, Bernreuther M, Huwer B, Neumann V, Schmidt JO (2011) Egg mortality: predation and hydrography in the central Baltic. ICES J Mar Sci 68:1379-1390

Walters CJ, Martell SJD (2004) Fisheries ecology and management. Princeton University Press, Princeton, NJ

- Watanabe Y, Zenitani H, Kimura R (1997) Variations in spawning ground area and egg density of the Japanese sardine in Pacific coastal and oceanic waters. Fish Oceanogr 6:35-40

Woillez M, Poulard JC, Rivoirad J, Petitgas P, Bez N (2007) Indices for capturing spatial patterns and their evolution in time, with application to the European hake (Merluccius productus) in the Bay of Biscay. ICES J Mar Sci 64:537-550

Zador S, Aydin K, Cope J (2011) Fine-scale analysis of arrowtooth flounder Atherestes stomias catch rates reveals spatial trends in abundance. Mar Ecol Prog Ser 438:229-239

Proofs received from author(s): January 21, 2013 